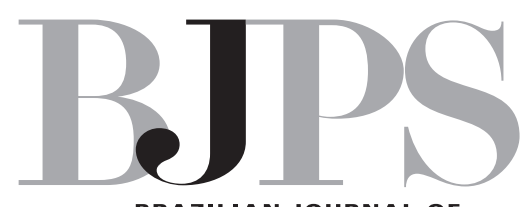

Brazilian Journal of

\title{
The new scenario of drug innovation
}

Drug innovation in pharmaceutical industries has gradually decreased after a boom in the 90's. Blockbusters were introduced and many scaffolds were discovered in this period, bringing new approaches to the therapeutics of some important diseases.

However, the first decade of the present century has facing a serious challenge on drug innovation. The reasons are different in their origins, one of them the costs and requirements for introducing a new drug in the pharmaceutical market. Although the financial needs are vertiginously increasing - the estimates today is about 1 billion dollars to introduce a new drug -- , the number of new drugs is significantly decreasing. In this context it is also important to consider that the success rate has been $20 \%$ in average, relatively to the amount of compounds/leads in development. Besides, the regulatory agencies have been more and more demanding toward the requirements for introducing safer drugs in the market. On the other hand, some experts have also considered the screening of leads based on only one target as responsible for the lack of innovation. This is true for some therapeutic classes, such as CNS drugs, for instance, but polypharmacology is now a trend in the search for new drugs.

This situation has favored the search of pharmaceutical industries for partnerships with universities, assuming that the academy could fulfill the lack of innovation they are facing nowadays. This is a unique opportunity for Pharmaceutical Sciences area. For this very reason, it is important to emphasize that this change in paradigm opens new horizons for those who have been working on drug design and development at the universities. Programs stimulating and supporting projects involving relationships between both segments have been created by Brazilian Foundations and funding agencies aiming at the search for new drug candidates. Diseases that were not considered so attractive by the pharmaceutical industries from different perspectives, including neglected diseases, have been the target for those integrated and multidisciplinary programs.

In Brazil, the investment in Research \& Development in Pharmaceutical Area has been increasing and this advance implies in qualification of human resources and also in partnerships with universities. In the last century, Brazil had not introduced any drug/medicine in the market. However, in the first decade of the 21th century, two new medicines have been launched and this stimulates more and more the Brazilian pharmaceutical industries toward innovation. 


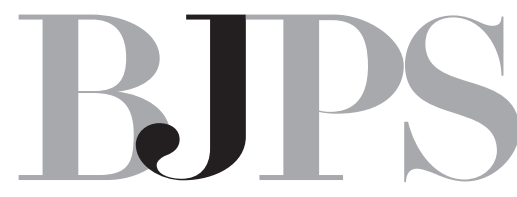

Brazilian Journal of Pharmaceutical Sciences

In this new situation, it is important for Brazilian schools of Pharmacy to strongly invest in subjects related to drug design and development, as for example Pharmaceutical/Medicinal Chemistry and Pharmaceutical Technology, in order to graduate professionals able to work on $P \& D$ in the pharmaceutical industries and on partnerships on the university side as well. Our industries need qualified professionals and to narrow the relationships with the academy in the corresponding area.

Finally, it is also interesting to mention that the scenario related to the countries that traditionally introduce more drugs into the market is gradually changing. The number of new drugs launched in Europe, Japan and also in the United States is decreasing, while it is increasing in other countries, particularly in China.

Hope Brazil can be among those nations soon in the future!

Elizabeth Igne Ferreira

Scientific Editor 